\title{
From the ICELW 2019 Conference Chair
}

\author{
https://doi.org/10.3991/ijac.v12i3.11835 \\ David Guralnick \\ International E-Learning and Kaleidoscope Learning, New York, New York
}

It has been my pleasure to chair the 12th annual International Conference on ELearning in the Workplace (ICELW) in 2019. We were very pleased to have Meredith Broussard and Dr. Scott Barry Kaufman as our keynote speakers, and a program featuring presenters from 25 countries. As the founding chair of ICELW, I have been very pleased to see the continued growth of the conference and the quality of work presented each year.

This special issue of iJAC features papers from the ICELW 2019 conference, some of which have been expanded or revised since their original ICELW version. Both ICELW and iJAC are avenues through which we can integrate research and practice in order to improve job performance. Our mix of researchers and practitioners at ICELW and in iJAC is, in my view, one of the strengths of both the conference and the journal, as we look to advance the field in ways that are practical yet based on research and theory.

I would like to thank all of our presenters and participants, as well as our Executive Committee, International Program Committee, keynote speakers, and our wonderful staff, for a great ICELW 2019, as we already look toward ICELW 2020. Next year's conference will be held from June 10-12, 2020, again at Columbia University in New York. As always, I look forward to seeing continued work from iJAC and ICELW play a major role in influencing and improving the field of e-learning in the workplace.

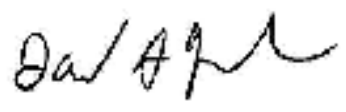

David Guralnick, Ph.D

Chair, International Conference on E-Learning in the Workplace

Editor, International Journal on Advanced Corporate Learning

President, International E-Learning Association

President, Kaleidoscope Learning

Adjunct Professor, Columbia University 